\title{
Accessory Breast Tissue in Pregnancy
}

\author{
Omeed Paknejad ${ }^{1,2}$, Dana Bryant' ${ }^{2}$, Carla Peterkin ${ }^{2}$, Wendy Wilcox ${ }^{2}$, Michele Follen ${ }^{2}$ \\ ${ }^{1}$ School of Medicine, Saint George's University, St. George, Grenada \\ ${ }^{2}$ Division of General Obstetrics, Division of Maternal Fetal Medicine, Kings County Hospital, Brooklyn, NY, USA \\ Email: *michelefollen@gmail.com
}

How to cite this paper: Paknejad, O., Bryant, D., Peterkin, C., Wilcox, W. and Follen, M. (2019) Accessory Breast Tissue in Pregnancy. Open Journal of Obstetrics and Gynecology, 9, 954-959.

https://doi.org/10.4236/ojog.2019.97092

Received: October 25, 2018

Accepted: July 5, 2019

Published: July 8, 2019

Copyright $\odot 2019$ by author(s) and Scientific Research Publishing Inc. This work is licensed under the Creative Commons Attribution International License (CC BY 4.0).

http://creativecommons.org/licenses/by/4.0/

(c) (i) Open Access

\begin{abstract}
Accessory breast tissue development frequently occurs in addition to physiologic breast development and is a common congenital condition with an occurrence of $0.4 \%$ to $6 \%$ in women and $1 \%-3 \%$ in men. A 31-year-old G1P0 female presented to our triage at $20+4$ weeks gestation with a one-week history of painful bilateral axillary lumps. Her last menstrual period was consistent with an estimated gestational age of $39+3$ weeks by LMP. She had emigrated from Bengal three years earlier with no other gynecological complaints and knew of no abnormalities on physical exam. The painful axillary lumps were found to be accessory breast tissue. This entity is presented as a palpable thickening that is most prevalent along the milk line in the region immediately below the breasts, along the abdomen, in the axilla and in the groin region adjacent to the vulva. Affected individuals may undergo premenstrual changes such as tenderness, swelling, and difficulty with shoulder range of motion and irritation. The onset of pregnancy stimulates the tissue and makes it more evident as it did with our patient.
\end{abstract}

\section{Keywords}

Accessory Breast Tissue, Pregnancy, Axilla, Milk Line, Polymastia, Supernumerary Nipples

\section{Introduction}

The development of accessory breast tissue can be traced back to the developmental period during the $5^{\text {th }}$ week of gestation when there is a thickening of the ectoderm known as the mammary ridge on the ventral surface of the developing embryo. The mammary ridge correlates closely with the milk line (60\% to $70 \%$ of cases) and normally will regress to a single pair of breasts on the pectoral region as the embryo continues to develop over the ensuing months [1]. The milk line extends from the anterior thorax down to the abdomen and into the groin. 
It is the failure of the mammary ridge to regress which results in accessory breast tissue. See Figure 1. The etiology, presentation, associated symptoms, pertinent differentials, methods of detection and treatment options for accessory breast tissue will be discussed herein.

\section{Case}

Our patient was designated as high risk due to diabetes and as such had scheduled weekly prenatal visits. She presented for prenatal care and bilateral accessory breast tissue nearby her axillae of 1 week duration. We communicated with the patient through a Cyracom interpreter. The patient endorsed changes coinciding with her menses consisting of fibrocystic changes in her breasts, as well as bilateral tender engorgements near her axillae. Prior to her visit, our patient was unaware of the possibility that these tender engorgements could be associated with accessory breast tissue. Bedside ultrasound was performed on the axillary engorgements to elucidate whether these masses were solid or cystic in nature. An echogenic area with an appearance paralleling that of typical breast tissue was visualized. Her history of cyclic premenstrual bilateral tender engorgements, physical examination (visual inspection and palpation) and sonographic findings allowed us to make a diagnosis of bilaterally axillary accessory breast tissue. On physical examination, there were no additional lesions visible or palpable along the milk line. She subsequently delivered a healthy baby and elected not to breast feed. The axillary breast tissue decreased in size over the ensuing month.
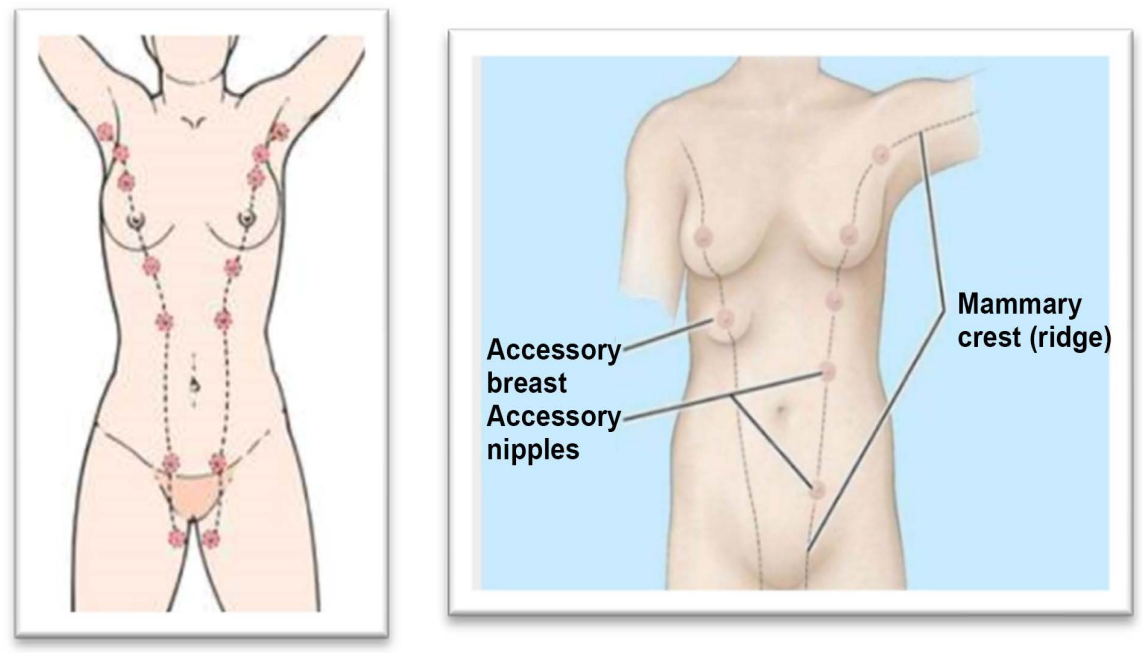

Figure 1. The "Milk Line". In embryonic development, the milk line is a ridge of ectodermal cells atop a strip of condensed cells from the mesoderm. It extends from the anterior thorax down to the groin and serves as a region of breast development in mammals. Left: Qph.fs.quoracdn.net. (2018). [online] Available at:

https://www.medicinenet.com/breast_anatomy/article.htm\#how_are_human_breasts_diff erent_from_other_species. Right: Image.slidesharecdn.com. (n.d.). [online] Available at: https://image.slidesharecdn.com/anatomyofthebreast-140405074307-phpapp01/95/anato my-of-the-breast-22-638.jpg?cb=1396683995. 


\section{Discussion}

\subsection{Classification}

Accessory breast tissue development can take many forms and in the literature accessory breast tissue has been reported as polymastia, supernumerary breasts, and ectopic breasts. Accessory breast tissue was historically classified into eight subcategories which have since been simplified to the following: accessory breast tissue (otherwise known aspolymastia), polythelia, and aberrant breast tissue [2] See Figure 2 and Table 1. Accessory and aberrant breast tissue have a high occurrence on the thorax, abdomen and within the axilla while polythelia is more common in the sternal region. Accessory breast tissue has been reported in the vulvar area. Polythelia is the presence of a/an accessory nipple(s) or areole without any associated glandular tissue. Aberrant breast tissue is the existence of disorganized secretory glandular tissue that is unrelated to the skin above it [2]. See Figure 3.

\subsection{Presentation}

Accessory breast tissue frequently occurs in addition to physiologic breast development and is a relatively common congenital condition [3]. While no population-based studies have been used to measure the incidence, the literature describing the entity shows case reports and case series from general surgeons, radiologists, gynecologists, and plastic surgeons. These physicians have an interest in the entity and may be seeing more of these patients than other providers. This would make their estimates falsely elevated. In some case series, authors believe the entity presents more frequently on the left side of the body as an isolated entity [1]. Accessory breast tissue may or may not occur in pairs, and it may
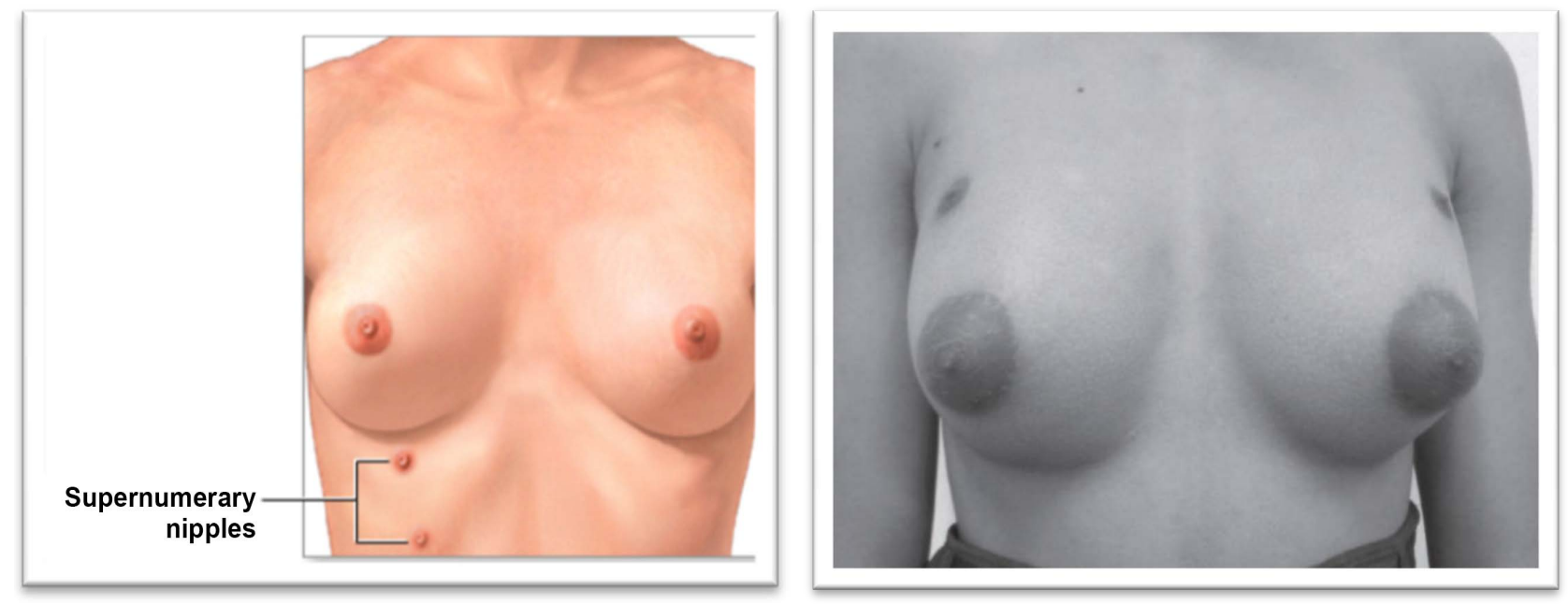

Figure 2. Polythelia. Polythelia is the occurrence of accessory nipples and/or areola without the presence of breast tissue. Polythelia frequently occurs on the anterior thorax. Left: Eclinicalworks.adam.com. (n.d.). Supernumerary nipples. [online] Available at: http://eclinicalworks.adam.com/content.aspx?productId=39\&pid=1\&gid=003110\&print=1. Right: Halleland, H. H., Balling, E., Tei, T., Arcieri, S., Mertz, H., \& Mele, M. (2017). Polythelia in a 13-year old girl. Il Giornale di chirurgia, 38(3), $143-146$. 

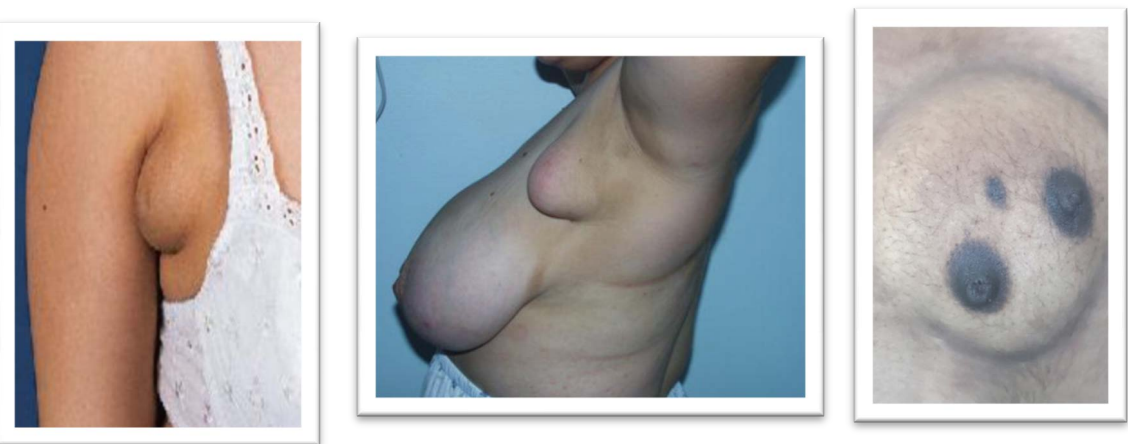

Figure 3. Accessory breast tissue. Accessory breast tissue most commonly develops in the axilla, but can develop anywhere along the milk line such as on the abdomen or groin, and may even develop ectopically along the dorsal surface (back). Left: Aafp.org. (2018). [online] Available at: https://www.aafp.org/afp/2000/0501/afp20000501p2799-f2.jpg.

Middle: Gentile, P., Izzo, V. and Cervelli, V. (2018). Fibroadenoma in the Bilateral Accessory Axillary Breast. [online] SpringerLink. Available at:

https://link.springer.com/article/10.1007/s00266-010-9505-y. Right: Gandhoke, C. S., Syal, S. K., Singh, H., Singh, D., \& Saran, R. K. (2018). Dorsal accessory ectopic breast with polythelia-A marker of occult spinal dysraphism. Surgical neurology international, 9, 143. https://doi.org/10.4103/sni.sni_34_18.

Table 1. Clinical categories of breast configuration. A classification system for mammary tissue malformations was presented by Kajava in 1915 which included the following definitions: 1) Complete supernumerary nipple-Nipple, areola and glandular breast tissue; 2) Supernumerary nipple (polymastia) -Nipple and glandular tissue (no areola); 3) Supernumerary nipple (polymastia)-Areola and glandular tissue (no nipple); 4) Aberrant glandular tissue only.

\begin{tabular}{cccc}
\hline Category & Nipple & Areola & Gland \\
\hline Normal Breast or Complete Supernumerary Nipple & + & + & + \\
Polymastia & $+/-$ & $+/-$ & + \\
Polythelia & + & - & - \\
Aberrant Gland Tissue & - & - & + \\
\hline
\end{tabular}

occur onother regions of the body aside from the milk line such as the buttocks, face, $\operatorname{arm}(\mathrm{s})$ and/or thigh(s); accessory breast tissue is not exclusive to the milk line, and when accessory breast tissue develops in non-milk line regions it is called ectopic breast [1].

\subsection{Differential Diagnosis}

Accessory breast tissue presents as a palpable thickening that is most prevalent along the milk line in the region immediately below the breasts, along the abdomen, in the axilla and along the groin region adjacent to the vulva [1]. Affected individuals may undergo premenstrual changes such as tenderness, swelling, difficulty with shoulder range of motion and irritation. Puberty, menstruation and pregnancy will often cause engorgement of the accessory breast tissue due to the fluctuance of sex hormones which can incite pain and/or discomfort 
for the individual. As a result, accessory breast development is frequently not evident until puberty [4] [5]. Our patient had presented with a painful breast lump and endorsed a history of fibrocystic changes during her menses which could explain the similar pattern she was exhibiting during pregnancy. Fibrocystic changes would be a reasonable differential for our patient, however the primary diagnosis of accessory breast tissue was better supported by her clinical presentation and findings on sonography.

\subsection{Diagnosis}

Accessory breast tissue can be diagnosed through physical examination, and sonography can be used in conjunction as it is helpful in distinguishing whether accessory breast tissue is present in the region of interest. Both ultrasound and MRI could be used to confirm the presence of glandular tissue. Fine needle aspiration cytology is another tool that may be utilized if a mass is suspected [3]. Accessory breast tissue is constituted by the same tissue-type found in a regular breast, and as such is prone to the same physiological and pathological changes seen in a normal breast. Case reports have shown that ectopic breast tissue may develop benign fibroadenomas and even breast cancers [3]. Both physical examination and ultrasound were used to support the diagnosis of accessory breast tissue in our patient.

\subsection{Treatment}

Treatment for accessory breast tissue is most often supportive as the condition is often benign. Surgery is considered when there is malignancy or malignancy potential, difficulty with shoulder range of motion, engorgement during menstruation, or any cosmetic concerns [5]. Liposuction is a documented alternative if surgery cannot be performed [1].

\subsection{Follow Up}

Patients should be followed annually to be certain that no masses develop in the accessory breast tissue. If masses develop, a needle biopsy should be performed to rule out malignancy.

\section{Conclusion}

Accessory breast tissue is a relatively common congenital condition that can be diagnosed through physical examination in conjunction with ultrasound and/or MRI imaging technique. The accessory breast tissue is the same type found in a regular breast and is thus prone to the same physiological and pathological changes. The clinician should be prepared for an array of possible issues that may arise with accessory breast tissue, ranging from benign breast tissue and/or fibroadenomas to malignant breast cancers. A patient with accessory breast tissue in pregnancy and her fetus will have an excellent overall prognosis with supportive treatment. 


\section{Conflicts of Interest}

The authors declare no conflicts of interest regarding the publication of this paper.

\section{References}

[1] Sahu, S., Husain, M. and Sachan, P. (2007) Bilateral Accessory Breast. The Internet Journal of Surgery, 17, 1-4.

[2] Arora, B.K., Arora, R., Aora, A. and Singh, K. (2016) Axillary Accessory Breast: Presentation and Treatment. International Surgery Journal, 3, 2050-2053. https://doi.org/10.18203/2349-2902.isj20163571

[3] Khatib, Y., Kashikar, A., Patel, R.D. and Shrestha, M. (2015) Varied Presentations of Ectopic Breast-Polymastia, Fibroadenoma, and Carcinoma Arising from Ectopic Breast Tissue. Clinical Cancer Investigation Journal, 4, 539-542.

http://www.ccij-online.org/text.asp?2015/4/4/539/159786 https://doi.org/10.4103/2278-0513.159786

[4] Loukas, M., Clarke, P. and Tubbs, R.S. (2007) Accessory Breasts: A Historical and Current Perspective. The American Surgeon, 73, 525-528. https://www.ncbi.nlm.nih.gov/pubmed/17521013

[5] Patel, P., Ibrahim, A., Zhang, J., et al. (2012) Accessory Breast Tissue. https://www.ncbi.nlm.nih.gov/pmc/articles/PMC3336208/ 